\title{
A potential role of mesenchymal stem cells derived from human umbilical cord blood in ameliorating psoriasis-like skin lesion in the rats
}

\author{
S.S. Attia, M. Rafla, N.E. El-Nefiawy, H.F. Abdel Hamid, M.A. Amin, M.A. Fetouh \\ Department of Anatomy and Embryology, Faculty of Medicine, Ain Shams University, Abbasia, Cairo, Egypt \\ [Received: 22 May 2021; Accepted: 5 July 2021; Early publication date: 3 August 2021]
}

Background: Psoriasis is a common autoimmune inflammatory skin disease, with no clear cause, treated with topical agents and phototherapy, conventional immunosuppressant drugs and biologic agents. Stem cell therapy has generated significant interest in regenerative medicine. The aim of this study was to use mesenchymal stem cell (MSC) therapy compared to the topical application of the standard conventional corticosteroid cream.

Materials and methods: Forty male adult albino rats were used, divided into four groups, 10 rats each: group I (control), group II (psoriasis-like lesions induced by usage of Aldara cream), group III (treated with betamethasone) and group IV (treated with MSCS). Specimens were stained with haematoxylin and eosin, Masson's trichrome, immune-histochemical technique for CD4, CD8 and CD31. Ultra-sections were prepared for transmission electron microscope (TEM) examination.

Results: Mesenchymal stem cells demonstrated efficacy in reduction of disease severity in the form of uniform epidermal thickness covered by a very thin keratin layer. Normally arranged layers of epidermal layers, with a clear border demarcation, were seen between the epidermis and the dermis with apparently intact basement membrane. TEM showed absence of gaps between the tightly connected cells of the basal layer and the resting basement membrane.

Conclusions: Application of MSCs raises hope for developing a new, safe and effective therapy for psoriatic patients, avoiding the side effects of betamethasone. (Folia Morphol 2022; 81, 3: 614-631)

Key words: psoriasis, human umbilical cord blood-derived mesenchymal stem cells, rat, imiquimod cream, CD4, CD8, CD31, electron microscopy

\section{INTRODUCTION}

Psoriasis is a common autoimmune chronic inflammatory skin disease, with no clear cause, that affects $2-3 \%$ of the world's population and greatly impairs the quality of life of affected individuals. Pso- riasis vulgaris or plaque psoriasis, the most prevalent disease type, it is characterised by well-demarcated, red, scaly plaques. Psoriasis-affected skin has a thickened epidermis with scaly patches, due to excessive proliferation and aberrant differentiation of kerat-

Address for correspondence: M.A. Fetouh, MD, Department of Anatomy and Embryology, Faculty of Medicine, Ain Shams University, P.O. box 11381, Abbasia, Cairo, Egypt, tel: +202 01001092511, e-mail: marwa_ali@med.asu.edu.eg; marwaabdelmoneim42011@gmail.com The work was conducted in Ain Shams University Faculty of Medicine.

This article is available in open access under Creative Common Attribution-Non-Commercial-No Derivatives 4.0 International (CC BY-NC-ND 4.0) license, allowing to download articles and share them with others as long as they credit the authors and the publisher, but without permission to change them in any way or use them commercially. 
inocytes, and redness that is caused by increased dilatation of the dermal blood vessels, and infiltration of immune cells [1].

It is considered to be a systemic disease rather than one limited to the skin as in certain cases, the cutaneous immune response becomes no longer restricted to the skin and results in systemic inflammation leading to the development of comorbidities. The pathogenesis of psoriasis has an immunological basis. A central role is played by Thelper (Th) 1 and Th17 lymphocytes and by cytokines. Th17 cells are involved not only in psoriasis but also in other autoimmune diseases; therefore, the involvement of the immune system in psoriasis is widely accepted now [25].

The treatment varies, depending on disease severity, from topical agents and phototherapy to conventional immunosuppressant drugs and biologic agents. However, they are expensive and several adverse reactions have been also reported [14]. Therefore, there is an unmet need for the development of a safe and effective therapy.

Stem cell therapy has evoked great expectations and showed significant interest in regenerative medicine. Mesenchymal stem cells (MSCs) are multipotent non-haematopoietic stromal cells. They can be isolated from bone marrow, umbilical cord blood and adipose tissue [19]. Because of their ability to modulate immune responses, MSCs are considered to be a therapeutic approach for the treatment of patients with systemic lupus erythematosus, rheumatoid arthritis, graft-versus-host disease, Crohn's disease, and multiple sclerosis $[8,10,41]$.

Reviewing the literature, few recent animal studies that investigated the potential use of stem cell therapy, of different origins, in the treatment of psoriasis were found. Human embryonic MSCs, adult human MSCs, and human umbilical cord-derived MSCs were used by the authors respectively $[21,23,36]$.

Here, the present study was conducted to examine the therapeutic scope of the human umbilical cord-derived mesenchymal stem cells (hUCB-MSCs) in the treatment of psoriasis using imiquimod (IMQ) -induced psoriasis rat model. Stem cell therapy was compared with the topical application of the standard conventional corticosteroid cream. hUCB-MSCs have been selected in the present study due to the lack of ethical considerations and the easy access to them following Lee et al. [23]. Light microscopic, immunohistochemical, transmission electron microscopic
(TEM) methods were utilised in this study in addition to morphometry and image analysis.

\section{MATERIALS AND METHODS}

Animals

Forty male adult albino rats weighing 180-200 g were obtained from Ain Shams University Faculty of Medicine research centre (MASRI). Rats were housed in stainless steel cages, 2 rats per cage, and were left for a week before any intervention to acclimatize to experimental conditions. The rats were exposed to 12 hours light/dark cycle and allowed free access to food and water (ad libitum) with suitable environmental conditions and good ventilation.

\section{Ethical consideration}

All the experimental protocols were carried out in accordance with the guidelines approved by the Committee of Animal Research Ethics, Faculty of Medicine Ain Shams University, which conforms to the legal requirements in Poland and EU Directive 2010/63/ /EU of the European Parliament and the Council of 22 September 2010 as well as the requirement of National Research Council 2011.

\section{Materials}

- Imiquimod (IMQ, 5\% cream, Aldara ${ }^{\circledR}$ ) in the form of sachets, each containing $250 \mathrm{mg}$ of cream, purchased from MEDA pharmaceutical company, Sweden.

- Betamethasone cream $(0.05 \%$ cream, Betamethasone ${ }^{\circledR}$ ) purchased from AMRIYA PHARM.IND, pharmaceutical company, Egypt.

- Xanthan gum (vehicle of the Aldara cream) purchased from Sigma chemical company (Cairo, Egypt), in the form of white dry powder. Two grams of xanthan gum were dissolved in $100 \mathrm{~mL}$ of normal saline.

\section{Isolation and culture of hUCB-MSCs}

Isolation and culture of hUCB-MSCs were performed in the Stem Cell Unit, Faculty of Medicine, Cairo University. The umbilical cord blood (UCB) samples were obtained from the umbilical vein immediately after delivery, with the informed consent of the mother. The UCB samples were mixed with Hetasep solution (stem cell technologies) at a ratio of $5: 1$, and then incubated at room temperature to deplete erythrocyte counts. The supernatant was collected carefully, and mononuclear cells were obtained using 
Ficoll density-gradient centrifugation at $2500 \mathrm{rpm}$ for 20 minutes. The cells were washed twice in phosphate buffered saline (PBS). Cells were seeded at a density of $2 \times 10^{5}$ to $2 \times 10^{6} \mathrm{cells} / \mathrm{cm}^{2}$ on plates in growth media that consisted of D-media and $10 \%$ foetal bovine serum. After 3 days, non-adherent cells were removed. The adherent cells formed colonies and grew rapidly, showing spindle-shaped morphology [22].

\section{Induction of psoriasis-like skin inflammation}

Psoriasis-like skin inflammation was induced according to the method of Chen et al. [7]. Briefly, rats received a daily topical dose of $62.5 \mathrm{mg}$ of Aldara ${ }^{\circledR}$ cream (5\%) containing $3.125 \mathrm{mg}$ of imiquimod (IMQ) on the shaved back skin for 12 consecutive days to achieve the optimal inflammation. Every cream sachet is containing $250 \mathrm{mg}$ of Aldara cream $(2 \mathrm{~mL}$ ) having $12.5 \mathrm{mg}$ of IMQ; therefore, the required single dose will be quarter of a sachet $(0.5 \mathrm{~mL})$. IMQ application was in the middle portion of the median sagittal plane of the back of each animal.

\section{Experimental groups}

Rats were randomly divided into four groups, 10 rats each:

- group I (control): subdivided into: group IA (negative control): included 5 rats that didn't receive any treatment; group IB (positive control): included 5 rats that received a daily topical dose of $0.5 \mathrm{~mL}$ of the vehicle of the cream (Xanthan gum in normal saline $200 \mathrm{mg} / 10 \mathrm{~mL}$ ) on the shaved back skin for 12 consecutive days used as a control group;

- group II (psoriasis): rats received a daily topical dose of $0.5 \mathrm{~mL}$ of Aldara ${ }^{\circledR}$ cream on the shaved back skin for 12 consecutive days;

- group III (psoriasis + betamethasone): rats received a combination of treatments. A daily topical dose of $0.5 \mathrm{~mL}$ of Aldara $^{\circledR}$ cream on the shaved back skin for 12 consecutive days. Then, on the $6^{\text {th }}$ day Betamethasone ${ }^{\circledR}$ cream $(0.05 \%)$ was applied twice daily till the $12^{\text {th }}$ day [26];

- group IV (psoriasis + hUCB-MSCs): rats received a combination of treatments. A daily topical dose of $0.5 \mathrm{~mL}$ of Aldara $^{\circledR}$ cream on the shaved back skin for 12 consecutive days. Then, on the $6^{\text {th }}$ day rats received one subcutaneous MSCs injection $\left(2 \times 10^{6}\right)$ cells per injection within $2 \mathrm{~mL}$ of the media) at the 4 corners around the edge of the inflamed area of the skin [23].

\section{Specimen collection}

On day 12 of the present experiment, animals were sacrificed using ether inhalation. Skin specimens were excised and some of them were fixed in 10\% neutral formalin in water for 48 hours and processed for light microscopic examination, while other specimens were fixed immediately in $2.5 \%$ glutaraldehyde and processed for TEM examination.

\section{Preparation of specimens for light microscopic examination}

Serial paraffin sections of $5 \mu \mathrm{m}$ thickness were cut and stained with haematoxylin and eosin (H\&E) and Masson's trichrome [11] for light microscopic examination.

\section{Immunohistochemistry technique}

The immunohistochemical staining was carried out using the avidine-biotin technique [2]. Samples from back skin ( $3 \mathrm{~mm}$ diameter) were immersed in TissueTek (Bayer), snap-frozen in liquid nitrogen, and stored at $-80^{\circ} \mathrm{C}$ until use. Six-micrometer cryosections of snap-frozen skin were cut using a cryostat (Jung Frigocut $2800 \mathrm{E}$; Leica). Sections were fixed in acetone (Fluka Chemie) containing $0.5 \% \mathrm{H}_{2} \mathrm{O}_{2}$ for 10 minutes at room temperature. Staining was performed essentially as described by van der Fits et al. [39]. Slides were incubated overnight at $4^{\circ} \mathrm{C}$, or for 1 hour at room temperature, with primary antibodies (Abs) against the following antigens (Ags) or cell types: CD4, CD8, CD31. This was followed by incubation for 30 minutes with biotin-linked secondary donkey-anti-rabbit, goat anti-hamster, or rabbit-anti-rat Abs and peroxidase-linked avidin (Dako).

\section{Preparation of skin specimens for TEM [2]}

The tissues were cut in slices $1 \mathrm{~mm}^{3}$ and fixed immediately in $2.5 \%$ buffered glutaraldehyde $(\mathrm{pH}$ 7.4) for 24 hours. The specimens were rinsed twice in phosphate buffer 20 minutes each. The specimens were post fixed in $1 \%$ osmic acid for 1 hour. Then tissues were washed twice in phosphate buffer, half an hour each. The specimen was put in a series of ascending grades of alcohol according to the following schedule: alcohol $50 \%$ for 10 minutes, alcohol $70 \%$ for 10 minutes, alcohol $80 \%$ for 10 minutes, alcohol $95 \%$ for 10 minutes, alcohol $100 \%$, two changes 10 minutes each. Clearing was performed in propylene oxide for 20 minutes at room temperature. Infiltration was done using equal parts of propylene 
oxide and Epon 812 and left in infiltration medium overnight. The sections were embedded in epoxy resin embedding media.

\section{Semi thin sectioning}

The block is cut into semithin sections $(1 \mu \mathrm{m})$ with a glass knife, using an ultramicrotome. The sections are then stained with Toluidine Blue for 25 seconds and examined by light microscope Olympus model BX51. Images were captured by camera Olympus model E-PM2 with $4608 \times 3072$-pixel format to determine the ultrathin area.

\section{Ultrathin sectioning}

Ultrathin sections were made at $50-70 \mathrm{~nm}$ using ultra-microtome Sumy Electron Optics (SEO) model UMTP-6M at thickness $90 \mathrm{~nm}$, mounted on copper grids (200 mesh).

Sections were stained with double stain (uranyl acetate $5 \%$ for $15 \mathrm{~min}$ followed by lead citrate for $8 \mathrm{~min}$ ).

\section{Electron micrographing}

Finally, sections were examined by TEM SEO model PEM-100, Faculty of Agriculture, Cairo University at different magnification. The photos were taken at $75 \mathrm{kV}$. Photos were captured by CCD camera JENOPTIK model ProgRes MFcool.

\section{Morphometric study and image analysis}

Haematoxylin and eosin-stained sections were used to assess the following parameters:

— thickness of the epidermis;

- blood vessels count;

— inflammatory cells count.

"Image J" computer image analysis software version $1.40 \mathrm{~g}$ was used to measure the previously mentioned parameters. For each of the previous entries, measurements were taken from 6 microscopic fields per slide, 6 slides per rat and 6 rats per group.

Counting the number of inflammatory cells per microscopic field was performed using the $(x 40)$ objective lens. Thickness of the epidermis and number of blood vessels per microscopic field were done using the $(\times 10)$ objective lens.

\section{Statistical analysis}

Statistical analysis was done using the SPSS software (Statistical Package for Social Studies, version 13.0). One-way analysis of variance (ANOVA) was employed to compare means in different groups with each other. Bonferroni post hoc test was used to detect significance between every two individual groups.

The significance of the data was determined by the probability ( $\mathrm{p}$ value). $\mathrm{P}>0.05$ was considered non-significant. $P \leq 0.05$ was considered significant and $p \leq 0.001$ was considered highly significant [37]. Data was represented in tables and histograms, prepared by using MS Excel 2013.

\section{RESULTS}

\section{Macroscopic results}

At the end of the experiment macroscopic examination of the mid-back skin of the rats that was shaved at the beginning of the experiment revealed the following: in the control group heavy hair regrowth was observed after 12 days and the skin appeared normal. In group II where the skin was subjected to topical application of IMQ cream for 12 days, well demarcated erythema with overlying scale like flakes (scaling) was found and hair regrowth was greatly hindered. In group III, the skin area that was subjected to betamethasone cream preceded by IMQ cream application revealed hair regrowth, no erythema but still there were some scales on the skin surface. In group IV, the skin area that was injected by subcutaneous MSCs preceded by IMQ cream application showed normal appearance of the skin with hair regrowth. No erythema or scales were observed (Fig. 1)

\section{Histological results Group I (control)}

Haematoxylin and eosin-stained sections from the control rats revealed the epidermis and dermis layers. The epidermis was composed of stratified squamous epithelium with uniform thickness and lies on a wavy basement membrane. The border between the epidermis and dermis was clearly demarcated. The epidermis appeared to be arranged into four layers and covered by keratin scales. It was composed of stratum basale; the cells of stratum basale were columnar in shape with basophilic cytoplasm. Above this layer, the stratum spinosum layer consisted of polyhedral acidophilic cells with rounded nuclei. The third layer, stratum granulosum, showed numerous basophilic granules (keratohyalin granules). Finally, the superficial stratum corneum appeared non-cellular and formed of acidophilic scales giving basket 


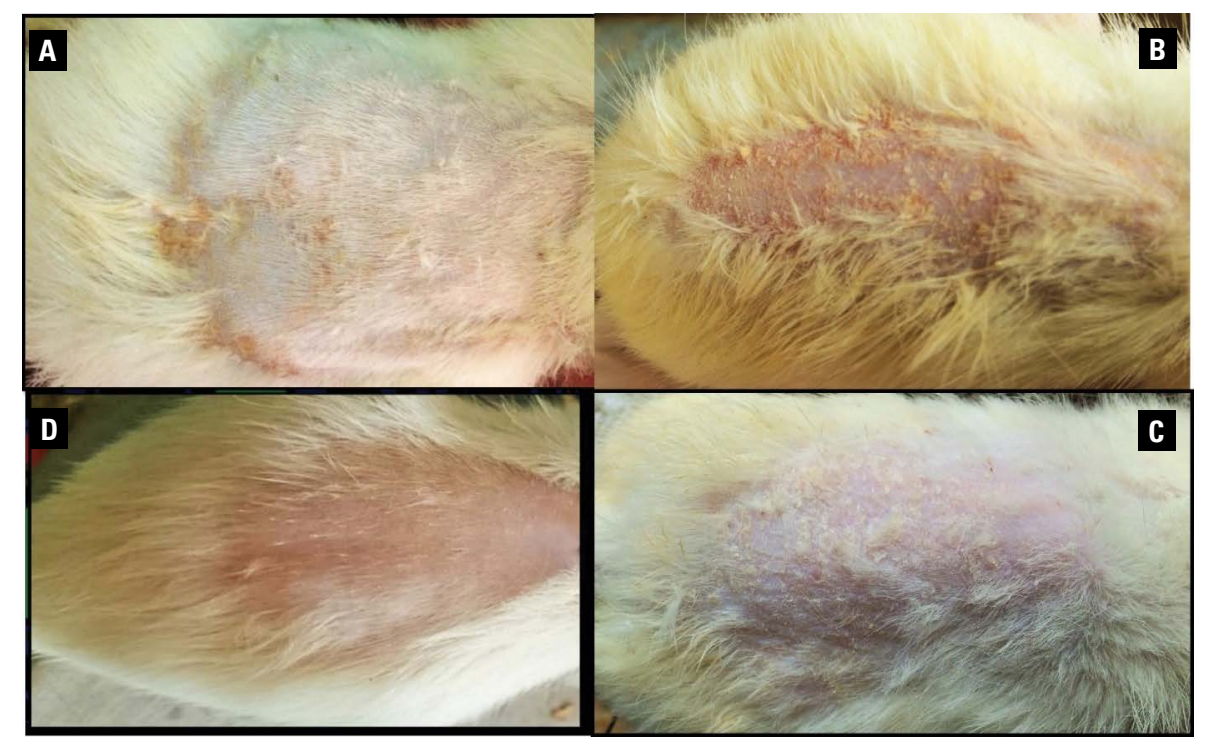

Figure 1. Gross appearance of: A. The normal control rat's skin showing heavy hair regrowth; B. The rat's skin that was treated with imiquimod (IMQ) cream for 12 days (group II). A well-demarcated erythema with overlying scale-like flakes (scaling) is observed. Note that hair regrowth is very weak; $C$. The rat's skin was topically treated by betamethasone cream preceded by IMO cream application (group III) showing hair regrowth. No erythema is observed but still there are some scales on the skin surface; $\mathbf{D}$. The rat's skin that received subcutaneous mesenchymal stem cells injection preceded by IM0 cream treatment (group IV) showing normal appearance of the skin with hair regrowth. No erythema or scales are observed.

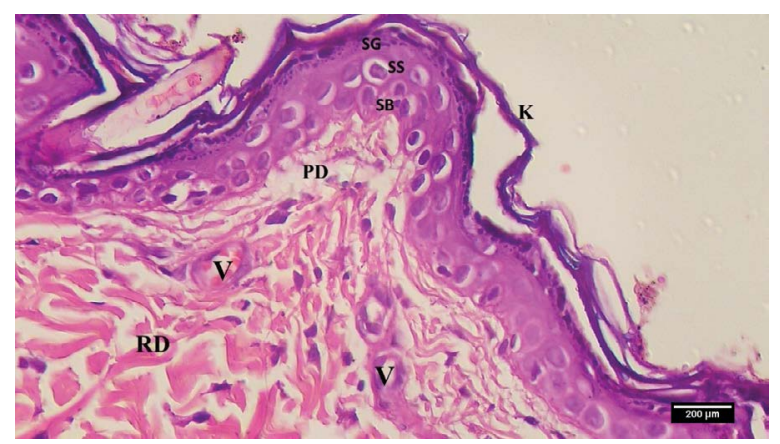

Figure 2. A light microscopic picture of a section in control rat's skin showing layers of the epidermis consisting of stratum basale (SB) which appears as basophilic columnar cells. Stratum spinosum (SS) appears as polyhedral acidophilic cells. Stratum granulosum (SG) appears containing numerous basophilic keratohyalin granules. Stratum corneum is the most superficial acellular layer and the covering acidophilic keratin scales $(\mathrm{K})$ appears as a basket weave. Uniform thickness of the epidermis is obvious through the whole section. Note the papillary layer (PD) and reticular layer (RD) of the underling dermis showing collagen bundles and few blood vessels $(\mathrm{V}) ; \mathrm{H} \& \mathrm{E}, \times 400$.

weave appearance. The underlying papillary layer of dermis showed fine collagen fibres, patent capillaries and many connective tissue cells. The inner reticular layer of dermis was composed of dense connective tissue rich in thick collagen fibres (Fig. 2).

Masson's trichrome-stained sections showed the papillary dermis with fine interlacing collagen fibres just below the epidermis. Deeper dense and thick

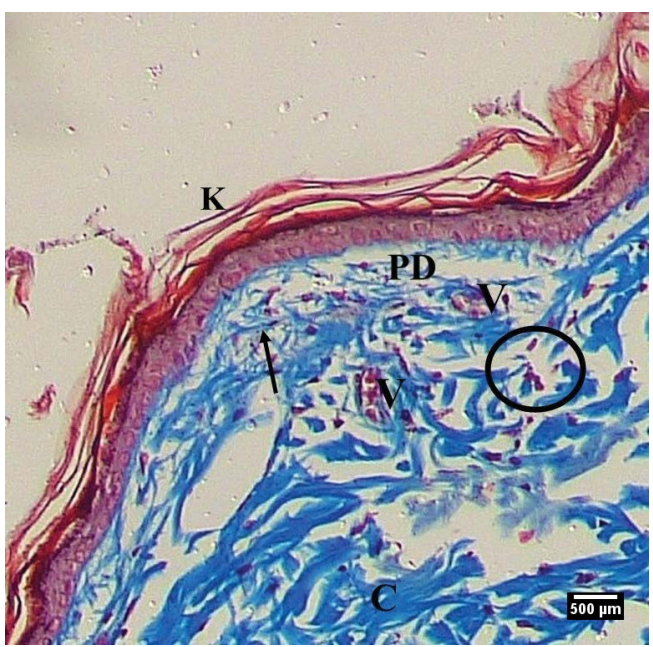

Figure 3. A light microscopic picture of a section in control rat's skin showing the papillary layer of dermis (PD) containing fine interlacing collagen fibres (arrow). The reticular layer of dermis (RD) contains thick wavy collagen fibres (C). The dermis apparently reveals few cellular elements (circle) and blood vessels (V). The epidermis is uniform in thickness with red keratin layer $(\mathrm{K})$ is seen on top; Masson's trichrome, $\times 100$.

wavy collagen fibres appeared in the reticular dermis (Fig. 3).

Immunohistochemical staining with CD31 revealed few, sporadic positively stained new vascular endothelial cells in the wall of the dermal blood vessels mainly in the papillary layer. The blood vessels appeared with thin wall and patent lumen (Fig. 4). 


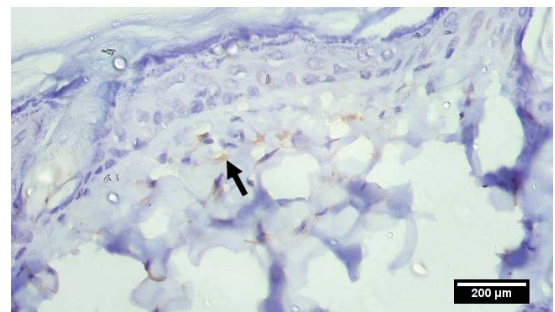

Figure 4. A light microscopic picture of an immunohistochemically stained sections with antibody for endothelial cells of the blood vessels in control rat's skin showing few, sporadic positively stained new vascular endothelial cells (arrow) in the wall of the dermal blood vessels mainly in the papillary layer; anti-CD31 antibody immune staining with Avidine-Biotin peroxidase method, $\times 400$.

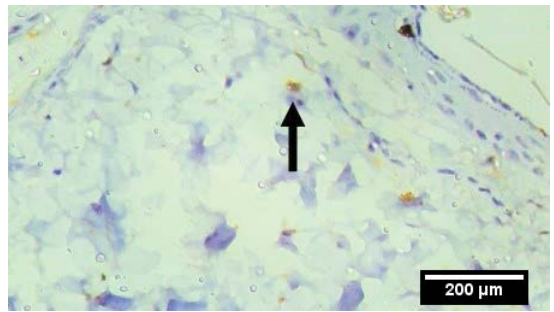

Figure 5. A light microscopic picture of an immunohistochemically stained sections with CD8 antibody in control rat's skin showing almost negative immune reaction with very few, sporadic positively stained cells (arrow) in the dermis (arrow); anti-CD8 immune staining with Avidine-Biotin peroxidase method, $\times 400$.

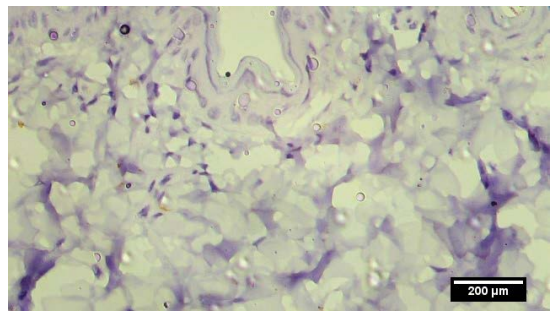

Figure 6. A light microscopic picture of an immunohistochemical stained sections of control rat's skin showing negative reaction for CD4 immune staining; anti-CD4 antibody immune staining with Avidine-Biotin peroxidase method, $\times 400$.

Immunohistochemical staining with CD8 antibody revealed negative immune reaction with very few, sporadic positively stained cells in the dermis (Fig. 5). Immunohistochemical staining with CD4 antibody showed negative reaction (Fig. 6).

\section{Group II (IMQ cream group)}

Haematoxylin and eosin-stained sections from group II that was treated with IMQ ream for 12 days revealed apparent thickening of the epidermis (epidermal hyperplasia), elongation of the rete ridges and thinning of supra-papillary plates

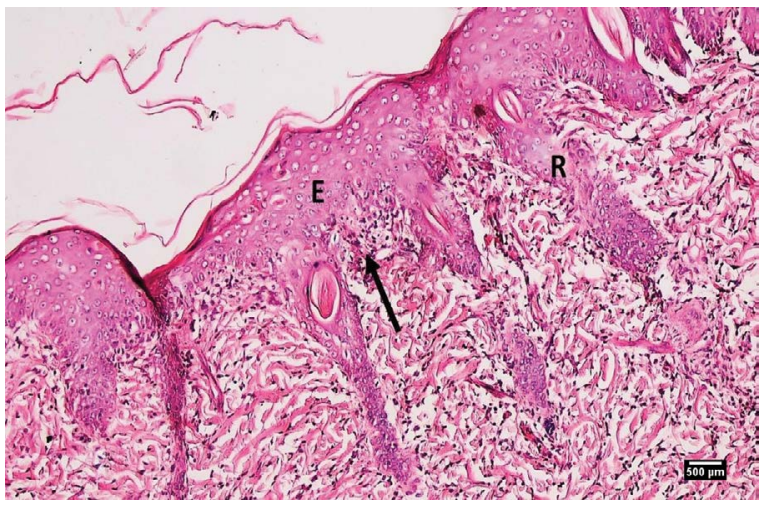

Figure 7. A light microscopic picture of a rat's skin section of the group that was treated with imiquimod cream for 12 days (group II). The photo demonstrates epidermal hyperplasia $(\mathrm{E})$. Elongation of the rete ridges $(\mathrm{R})$, collections of immune cell infiltration (arrow) in the papillary dermis. Note thinning of the supra-papillary plates $(p)$; $H \& E, \times 100$.

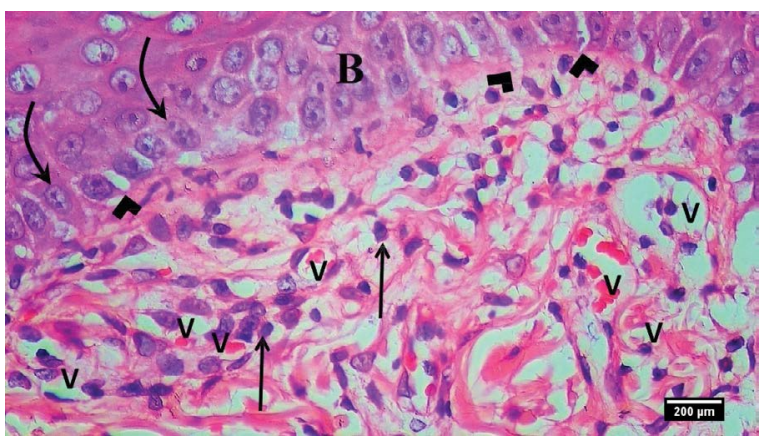

Figure 8. A light microscopic picture of a rat's skin section of the group that was treated with imiquimod cream for 12 days (group II) showing apparent proliferation of different layers of the epidermis with overcrowding of the cells at the basal layer (B). Mitotic figures are evident (curved arrow). Wide intercellular spaces between basal keratinocytes and gaps in the basement membrane underlying the epidermis and traversing inflammatory cells can be seen (arrowhead). There is no sharp demarcation between the epidermis and dermis (basement membrane is almost not visualised). Notice numerous blood vessels (V) and immune cell infiltration (arrow) in the underlying dermis; $H \& E, \times 400$.

(Fig. 7). The granular layer of the epidermis in which terminal differentiation begins was greatly reduced or absent, consequently a stratum corneum form incompletely differentiated keratinocytes that known as parakeratosis. Also, widening of the intercellular spaces between keratinocytes due to intercellular oedema known as spongiosis was seen. The basement membrane between epidermis and dermis appeared irregular and discontinuous at some area with traversing inflammatory cells into the epidermis (exocytosis). The underlying dermis showed increased angiogenesis and immune cell infiltration (Fig. 8). 


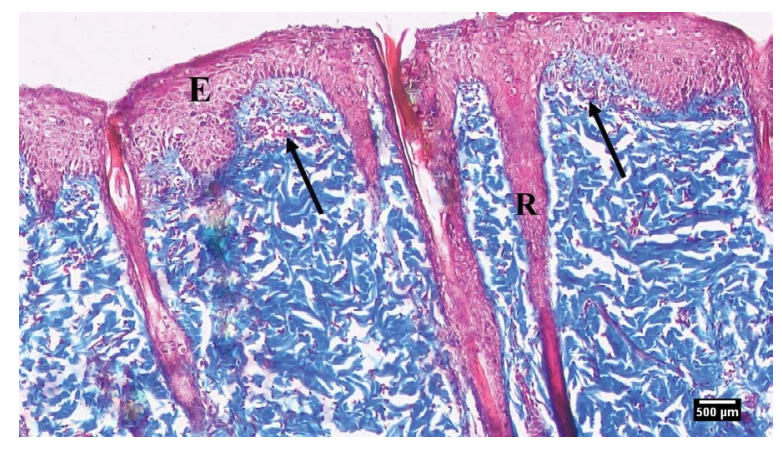

Figure 9. A light microscopic picture of a rat's skin section of the group that was treated with imiquimod cream for 12 days (group II) showing epidermal hyperplasia $(E)$, elongation of the rete ridges $(R)$. Numerous inflammatory cell infiltrate is seen in the dermis (arrow); Masson's trichrome, $\times 100$

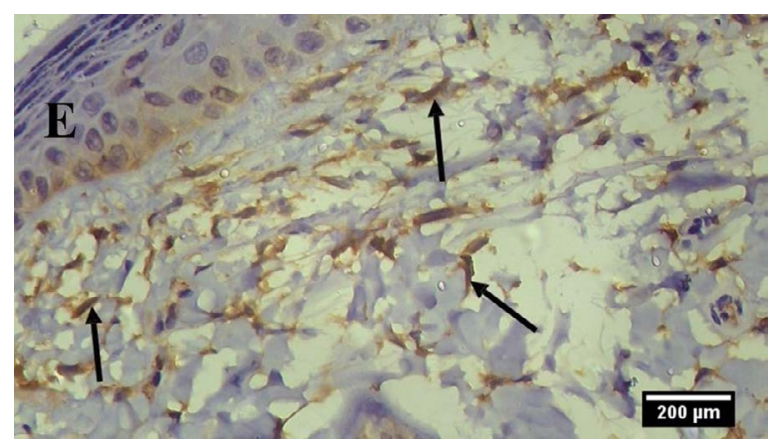

Figure 10. A light microscopic picture of an immunohistochemically stained sections with antibody for endothelial cells of the blood vessels in rat's skin section of the group that was treated with imiquimod cream for 12 days (group II). Plenty of positively stained new vascular endothelial cells (arrow) in the wall of the dermal blood vessels are seen mainly in the papillary layer of dermis. Notice also, the positive immune staining can be seen in some areas of the epidermis (E); anti-CD31 antibody immune staining with Avidine-Biotin peroxidase method, $\times 400$.

Masson's trichrome-stained sections showed epidermal hyperplasia, elongation of the rete ridges. Also, numerous inflammatory cell infiltrate was seen particularly in the superficial dermis (Fig. 9).

Immunohistochemical staining with CD31 revealed plenty of positively stained new vascular endothelial cells in the wall of the dermal blood vessels mainly in the papillary layer of dermis. The positive immune staining also was seen in some areas of the epidermis (Fig. 10). Immunohistochemical staining with $\mathrm{CD} 8$ antibody revealed positively immune stained CD8 cells in the papillary dermis. CD8 positive immune stained cells were visualised in the epidermis as well (Fig. 11). Immunohistochemical staining for CD4 showed positively immune stained CD4 cells in the papillary dermis. Positive CD8 and CD4 cells were

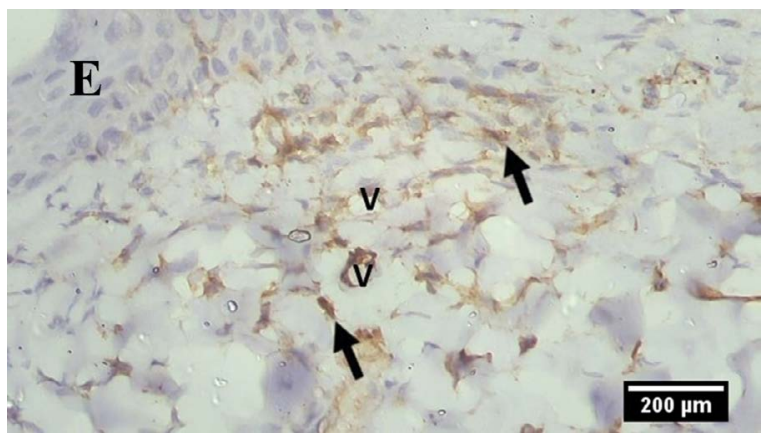

Figure 11. A light microscopic picture of an immunohistochemically stained sections with CD8 antibody in rat's skin sections of the group that was treated with imiquimod cream for 12 days (group II). Positively immune stained CD8 cells can be seen in the papillary dermis (arrow). Positive cells are located mainly around and nearby blood vessels (V). CD8 positive immune stained cells can be visualised in the epidermis as well (E); anti-CD8 antibody immune staining with Avidine-Biotin peroxidase method, $\times 400$.

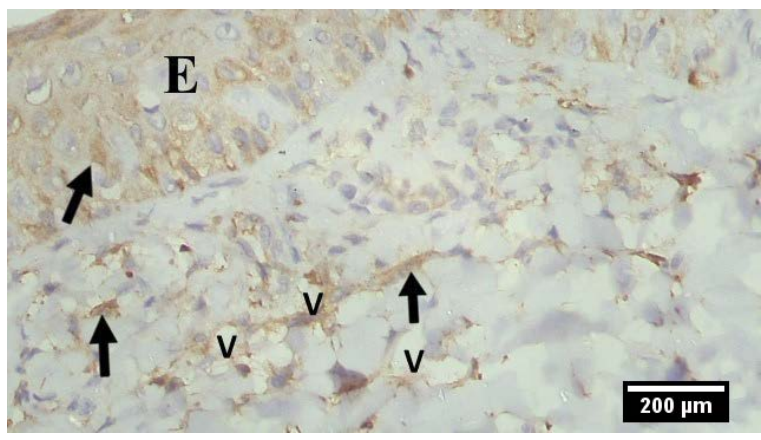

Figure 12. A light microscopic picture of an immunohistochemically stained sections with CD4 antibody in rat's skin sections of the group that was treated with imiquimod cream for 12 days (group II) showing positively immune stained CD4 cells in the papillary dermis (arrow). Positive cells are located mainly around and nearby blood vessels (V). CD4 positive immune stained cells can be visualised in the epidermis as well (E); anti-CD4 antibody immune staining with Avidine-Biotin peroxidase method, $\times 400$.

located mainly around and nearby blood vessels and both were visualized in the epidermis as well (Fig. 12).

\section{Group III (IMQ + betamethasone group)}

Haematoxylin and eosin-stained sections from the group that received betamethasone cream preceded by IMQ cream application revealed epidermis with uniform thickness covered with a thin layer of keratin. Elongation of the rete ridges into the underlying connective tissue of dermis also was seen. The epidermis was composed of 4 layers. Stratum basale was formed of crowded low columnar basophilic cells with basal oval nuclei that showed some mitotic figures. Above this layer, stratum spinosum was present and consisted of few acidophilic polygonal cells with frequent pyknotic nuclei and vac- 


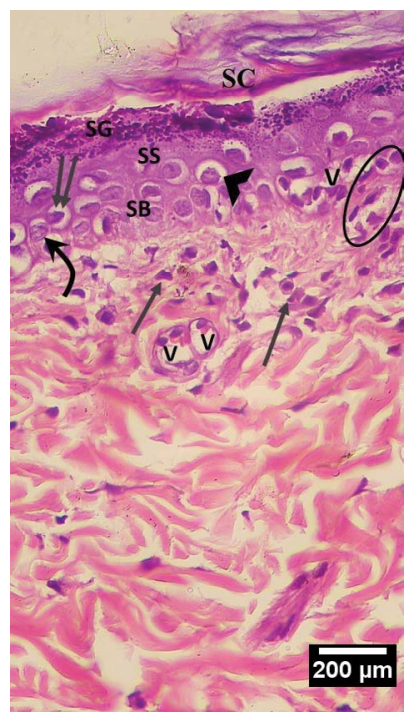

Figure 13. A light microscopic picture of a section in rat's skin of the group that received betamethasone cream preceded by imiquimod cream application (group III) showing the 4 layers of the epidermis. The photo displays crowded basal basophilic low columnar cells of stratum basale (SB) with some mitotic figures (short curved arrow). Note the large blood vessel containing many inflammatory cells that is located at the basal layer of the epidermis (V). Stratum spinosum (SS) appears as acidophilic polygonal cells with frequent pyknotic nuclei (double arrow) and vacuolations (arrowhead). Stratum granulosum (SG) appears as flat cells filled with many basophilic keratohyalin granules and apparently thick layer of acidophilic stratum corneum (SC). Notice that there is no sharp demarcation line between epidermis and dermis (no visible basement membrane) and travelling inflammatory cells into the epidermis is obvious (oblong shape). The underlying dermis demonstrates frequent blood vessels (V), and some collections of inflammatory cells (arrow); H\&E, $\times 400$.

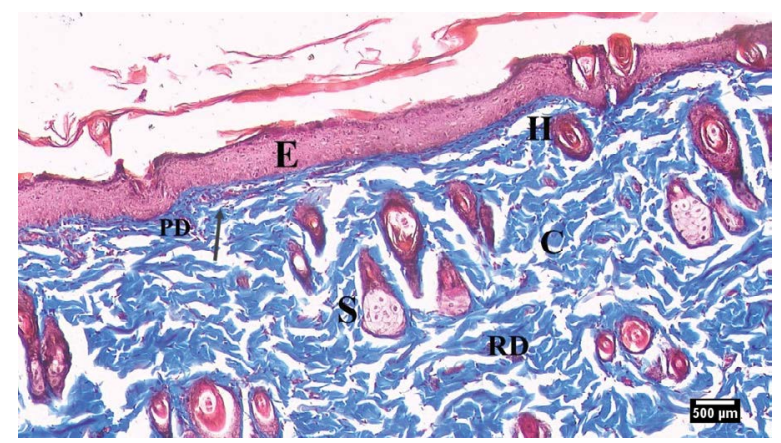

Figure 14. A light microscopic picture of a section in rat's skin of the group that received betamethasone cream preceded by imiquimod cream application (group III) showing thick hypertrophied epidermis (E). The underlying papillary layer of dermis (PD) containing fine interlacing collagen fibres (arrow). The reticular layer of dermis (RD) contains thick wavy collagen fibres (C). Numerous transversely cut hair follicles $(\mathrm{H})$ and sebaceous glands (S) are visible; Masson's trichrome, $\times 100$.

uolations. Stratum granulosum consisted of 2 rows of spindle-shaped cells with basophilic granular cytoplasm. Finally, the stratum corneum appeared to be formed of acidophilic thick layer. No sharp demarcation line be-

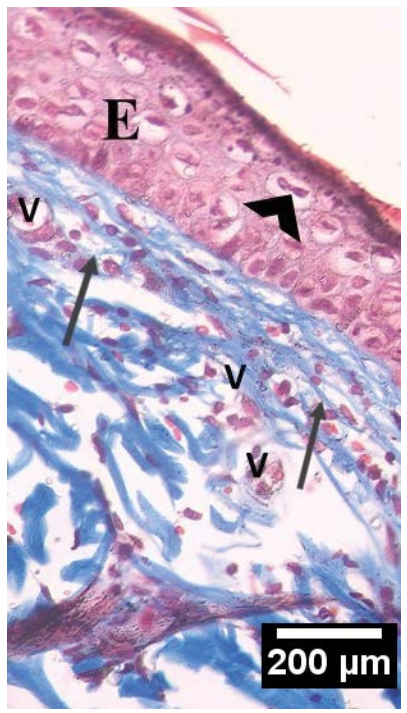

Figure 15. A higher magnification of Figure 14 showing the epidermis with crowded basal layer, many pyknotic nuclei (arrow head) in spongy layer. The underlying papillary dermis shows inflammatory cells (arrow) particularly localized around the dermal blood vessels (v); Masson's trichrome, $\times 400$.

tween epidermis and dermis was seen with travelling inflammatory cells into the epidermis. The underlying dermis showed frequent blood vessels and some collections of inflammatory cells (Fig. 13).

Masson's trichrome-stained sections showed crowded basal layer in the epidermis with many pyknotic nuclei in spongy layer. The underlying papillary dermis showed inflammatory cells particularly localized around the dermal blood vessels (Figs. 14, 15).

Immunohistochemical staining with antibody for endothelial cells of the blood vessels CD31 antibody immune stained with Avidin-Biotin peroxidase method revealed moderate number of positively stained new vascular endothelial cells in the wall of the dermal blood vessels mainly in the papillary layer (Fig. 16). Immunohistochemical staining for CD8 antibody revealed few sporadic positively immune stained CD8 cells in the papillary dermis (Fig. 17). Immunohistochemical staining for CD4 antibody revealed positively immune stained CD4 cells in the papillary dermis. Positive cells were located mainly around and nearby blood vessels (Fig. 18).

\section{Group IV (IMQ + hUCB-MSCS)}

Haematoxylin and eosin-stained sections from the group that received one subcutaneous umbilical cord derived MSCs injection preceded by IMQ cream revealed epidermis with uniform thickness that lied on a straight basement membrane and covered with 


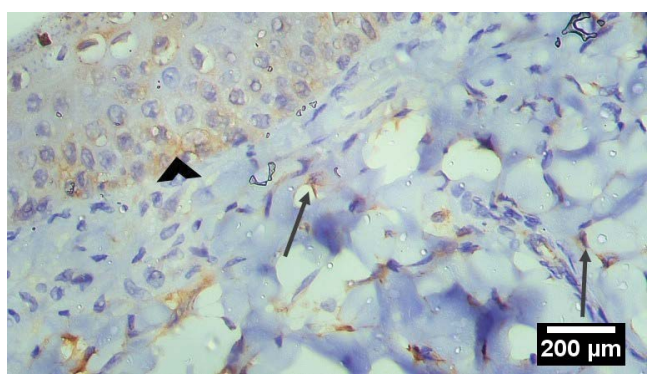

Figure 16. A light microscopic picture of an immunohistochemically stained sections with antibody for endothelial cells of the blood vessels in rat's skin of the group that received betamethasone cream preceded by imiquimod cream application (group III) showing moderate number of positively stained new vascular endothelial cells (arrow) in the wall of the dermal blood vessels mainly in the papillary layer. Also, positive immune stained cells are observed in the epidermis (arrowhead); anti-CD31 antibody immune staining with Avidine-Biotin peroxidase method, $\times 400$.

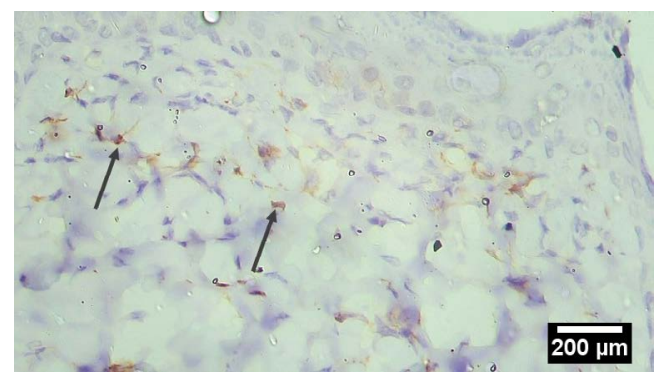

Figure 17. A light microscopic picture of an immunohistochemically stained sections with CD8 antibody in rat's skin sections of group that received betamethasone cream preceded by imiquimod cream application (group III) showing few sporadic positively immune stained CD8 cells in the papillary dermis (arrow); anti-CD8 antibody immune staining with Avidine-Biotin peroxidase method, $\times 400$.

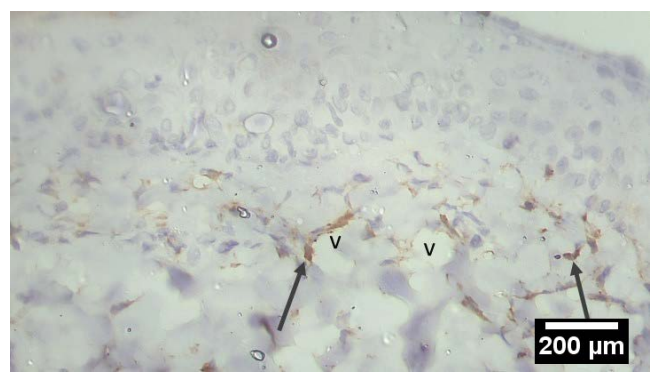

Figure 18. A light microscopic picture of an immunohistochemically stained sections with CD4 antibody in rat's skin sections of group that received betamethasone cream preceded by imiquimod cream application (group III) showing positively immune stained CD4 cells in the papillary dermis (arrow). Positive cells are located mainly around and nearby blood vessels (V); anti-CD4 antibody immune staining with Avidine-Biotin peroxidase method, $\times 400$.

a very thin keratin layer. The layers of the epidermis consisted of stratum basale which appeared as basophilic columnar cells resting on a straight continuous

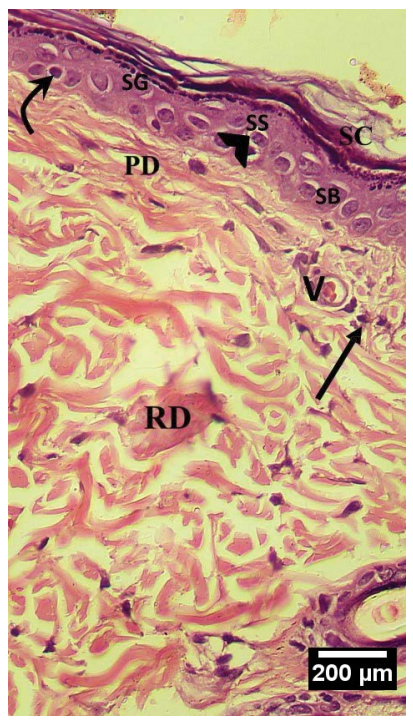

Figure 19. A light microscopic picture of a section of rat's skin of the group that received subcutaneous mesenchymal stem cells injection preceded by imiquimod cream application (group IV). The photo depicts layers of the epidermis consisting of stratum basale (SB) which appears as basophilic columnar cells resting on a straight continuous basement membrane, stratum spinosum (SS) appears as polyhedral acidophilic cells. Stratum granulosum (SG) appears containing numerous basophilic granules. Stratum corneum (SC) is the most superficial acellular layer. Some keratocytes show pyknotic nuclei (curved arrow), other reveal vacuolation (arrowhead). Uniform thickness of the epidermis is obvious through the whole section. Note the papillary layer (PD) and reticular layer (RD) of the underling dermis which demonstrate few blood vessels (V) and connective tissue cells (arrow); H\&E, $\times 400$.

basement membrane. Stratum spinosum appeared as polyhedral acidophilic cells. Stratum granulosum appeared containing numerous basophilic granules. Stratum corneum was the most superficial acellular layers. A clear border demarcation was seen between the epidermis and the dermis with apparently intact basement membrane. The underling dermis showed few blood vessels and connective tissue cells (Fig. 19).

Masson's trichrome-stained sections showed papillary layer of dermis containing fine interlacing collagen fibres. The reticular layer of dermis showed thick wavy collagen fibres. The sharp demarcation between the epidermis and dermis was evident (Fig. 20).

Immunohistochemical staining with CD31 revealed few, sporadic positively stained new vascular endothelial cells in the wall of the dermal blood vessels mainly in the papillary layer (Fig. 21). Immunohistochemical staining for CD8 and CD4 antibodies revealed negative immune reaction (Figs. 22, 23).

Using TEM, the epidermis of rat's skin of IMQ treated group II showed apparent proliferation of the epidermis with overcrowded basal layer which 


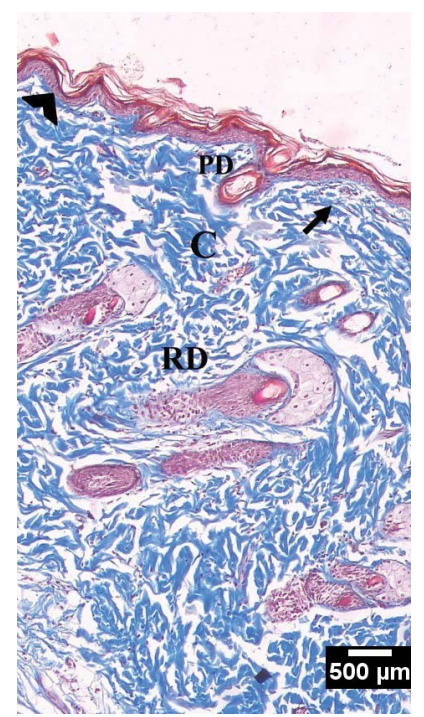

Figure 20. A light microscopic picture of a section in rat's skin of the group receiving subcutaneous mesenchymal stem cells injection preceded by imiquimod cream application (group IV) showing the papillary layer of dermis (PD) containing fine interlacing collagen fibres (arrow). The reticular layer of dermis (RD) contains thick wavy collagen fibres (C). Sharp demarcation between the epidermis and dermis is evident (arrowhead); Masson's trichrome, $\times 100$.

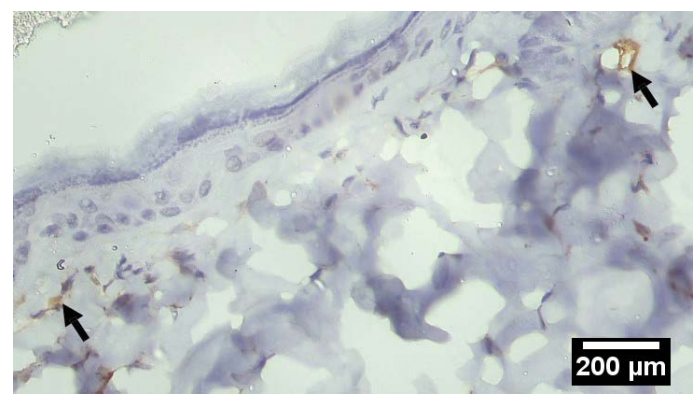

Figure 21. A light microscopic picture of an immunohistochemically stained sections with antibody for endothelial cells of the blood vessels in rat's skin of the group receiving subcutaneous mesenchymal stem cells injection preceded by imiquimod cream application (group IV) showing few, sporadic positively stained new vascular endothelial cells (arrow) in the wall of the dermal blood vessels mainly in the papillary layer; anti-CD31 antibody immune staining with Avidine-Biotin peroxidase method, $\times 400$.

was loosely attached to the resting basement membrane. Wide intercellular spaces within the basal layer and large gaps between them and the underlying basement membrane were obviously seen. While in the MSCs-treated group IV, there were no gaps seen between the tightly connected cells of the basal layer and the resting basement membrane (Fig. 24). In IMQ-treated group, the stratum basale cells resting on a basement membrane appeared irregular in shape with tendency of mitosis and division of its dense nucleolus with wide intercellular spaces. The resting

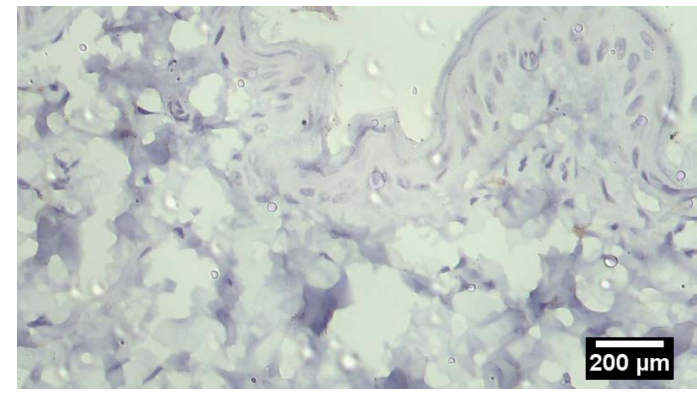

Figure 22. A light microscopic picture of an immunohistochemically stained sections with CD8 antibody in rat's skin of the group receiving subcutaneous mesenchymal stem cells injection preceded by imiquimod cream application (group IV) showing negative immune reaction; anti-CD8 antibody immune staining with Avidine-Biotin peroxidase method, $\times 400$.

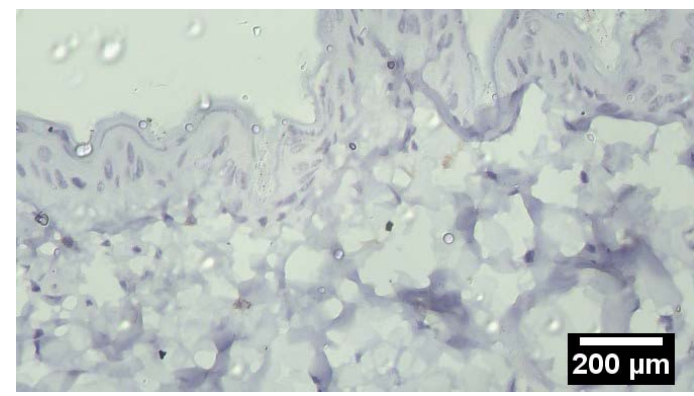

Figure 23. A light microscopic picture of an immunohistochemically stained sections with CD4 antibody in rat's skin of the group receiving subcutaneous mesenchymal stem cells injection preceded by imiquimod cream application (group IV) showing negative reaction for CD4 immune staining; anti-CD4 antibody immune staining with Avidine-Biotin peroxidase method, $\times 400$.

basement membrane showed large gaps and absence of hemidesmosomes connecting it to the basal layer. While in MSCs-treated group the stratum basale cells appeared columnar in shape with elongated euchromatic nucleus and dense nucleolus. These cells have processes that were connected tightly together by desmosomes and were connected with the basement membrane by hemidesmosomes (Figs. 25, 26, 27).

\section{Morphometric results and statistics Thickness of the epidermis}

Measuring of the epidermal thickness in H\&E-stained sections under high power field of light microscope revealed highly statistically significant increase in the epidermal thickness in group II (IMQ-treated) and the betamethasone-treated group III compared to the control (group I) $(p<0.001)$. In MSCs-treated group IV, there was a highly significant decrease in the epidermal thickness as compared to group II (IMQ-treated) $(p<0.001)$ (Table 1, Fig. 28). 

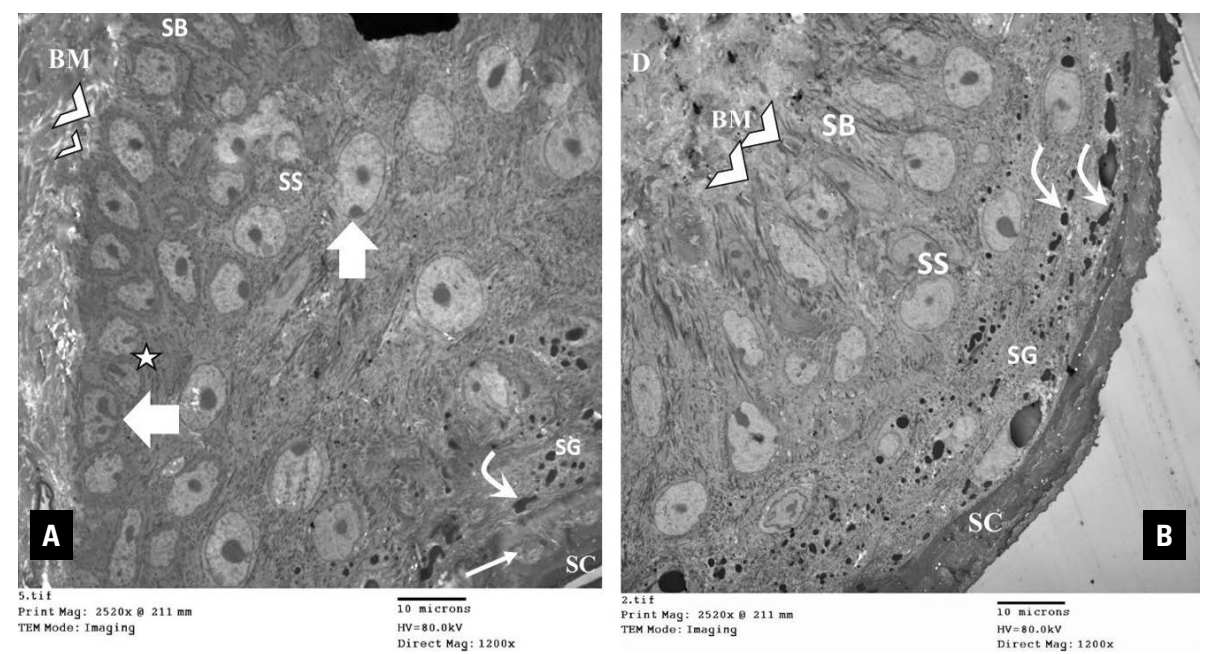

Figure 24. A. An electron photomicrograph of a section in the epidermis of rat's skin of the group that was treated with Aldara cream for 12 days showing apparent proliferation of different layers of the epidermis with overcrowding of the cells of the basal layer. Stratum basale (SB) cells resting on a loosely attached basement membrane (BM). The cells appear columnar in shape with elongated euchromatic nucleus and dense nucleolus; however, some cells appear irregularly in shape (asterisk). Notice the wide intercellular spaces within the basal layer and the large gaps (arrowhead) between them and the underlying basement membrane. In stratum spinosum (SS) keratinocytes are polygonal in shape with rounded euchromatic nucleus and electron dense nucleolus. Mitotic figures are evident (thick arrow). In stratum granulosum layer (SG), the cytoplasm of the cells contains few keratohyalin granules (curved arrow). Notice the superficial stratum corneum (SC) with many cytoplasmic and nuclear remnants (parakeratosis) (arrow); B. After receiving subcutaneous mesenchymal stem cells injection preceded by Aldara cream application showing stratum basale (SB) cells resting on a basement membrane (BM) separating it from the underlying dermis (D). the cells are connected with the basement membrane by hemidesmosomes (arrowhead). In stratum spinosum (SS) keratinocytes are polygonal in shape with rounded euchromatic nucleus and electron dense nucleolus. In stratum granulosum (SG) The cells have oblong euchromatic nucleus, the cytoplasm contains keratohyalin granules (curved arrow). Notice the superficial stratum corneum (SC) non-nucleated cells with electron dense patches of keratin; TEM $\times 1200$.

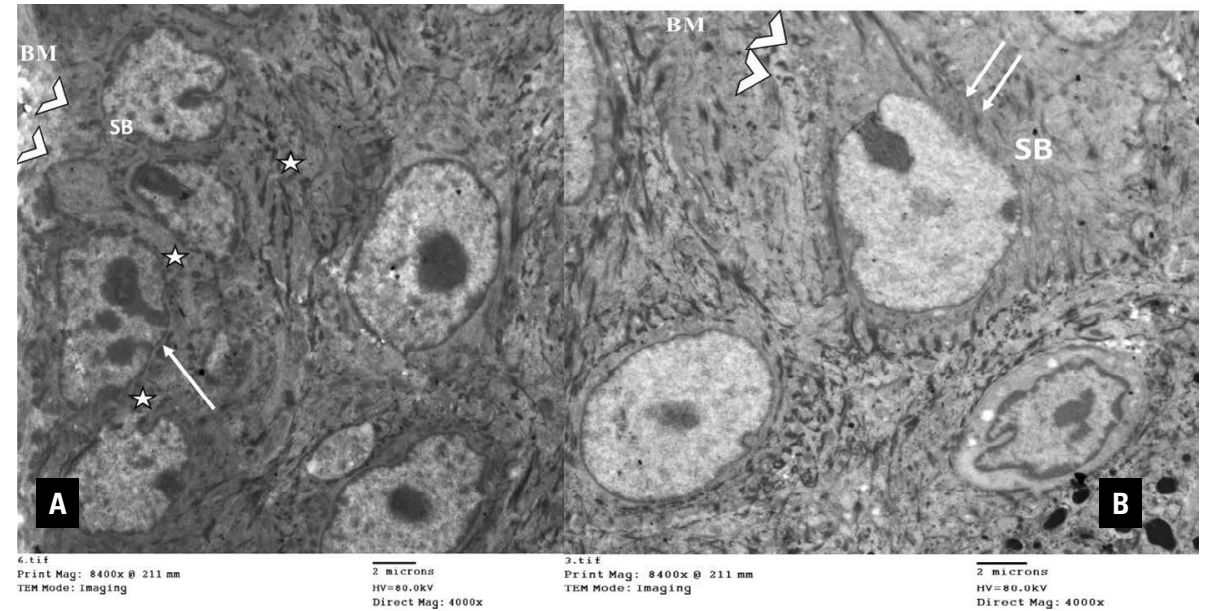

Figure 25. A. A higher magnification of a part of section of Figure 24A showing stratum basale (SB) cells resting on a basement membrane (BM). The cells appear irregular in shape with tendency of mitosis and division of its dense nucleolus (arrow). Notice the wide intercellular spaces between them $\left({ }^{*}\right)$. The resting basement membrane shows large gaps and absence of hemidesmosomes connecting it to the basal layer (arrowhead); B. After subcutaneous mesenchymal stem cells injection preceded by Aldara cream application showing stratum basale (SB) cells resting on a basement membrane (BM). The cells appear columnar in shape with elongated euchromatic nucleus and dense nucleolus. The cells have processes that are connected together by desmosomes (arrow) and are connected with the basement membrane by hemidesmosomes (arrowhead); TEM $\times 4000$.

\section{Blood vessels count}

Counting the number of new blood vessels in H\&E-stained sections under low power field of light microscope, revealed highly statistically significant increase in the number of new blood vessel formation in group II (IMQ-treated), significant increase in 

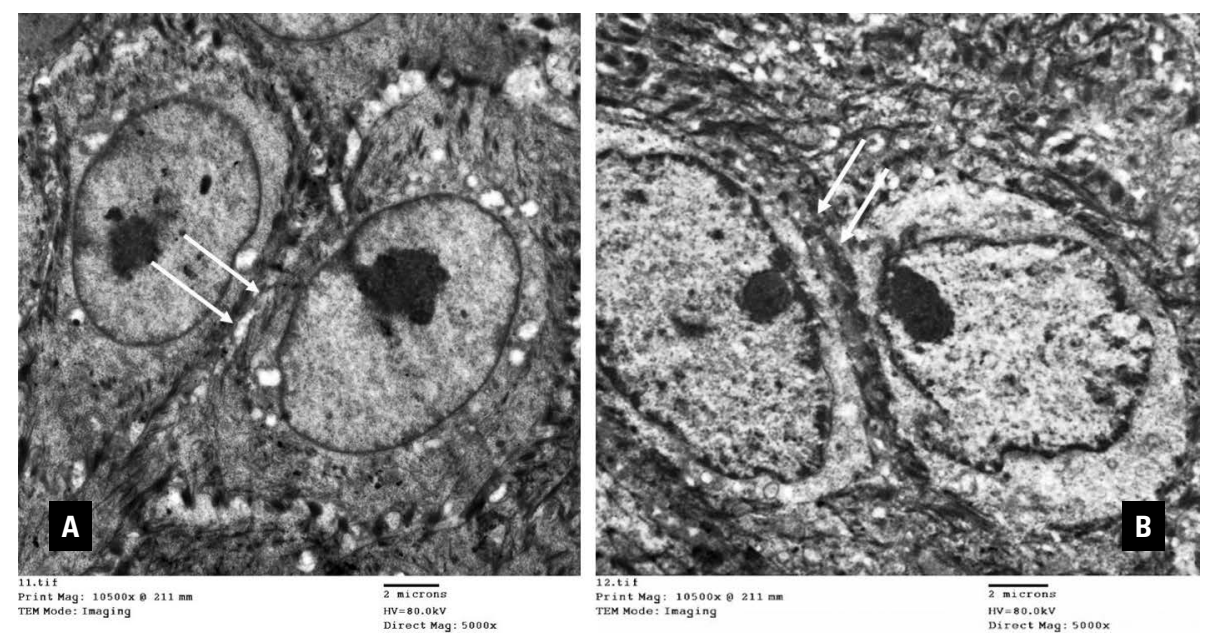

Figure 26. A. An electron photomicrograph of a section in the epidermis of rat's skin of the group that was treated with Aldara cream for 12 days showing stratum basale cells. The cells appear columnar in shape with elongated euchromatic nucleus and dense nucleolus. The cells show wide intercellular spaces where they lost their desmosomal connections (arrow); B. After receiving subcutaneous mesenchymal stem cells injection preceded by Aldara cream application showing stratum basale cells. The cells appear columnar in shape with elongated euchromatic nucleus and dense nucleolus; TEM $\times 5000$.

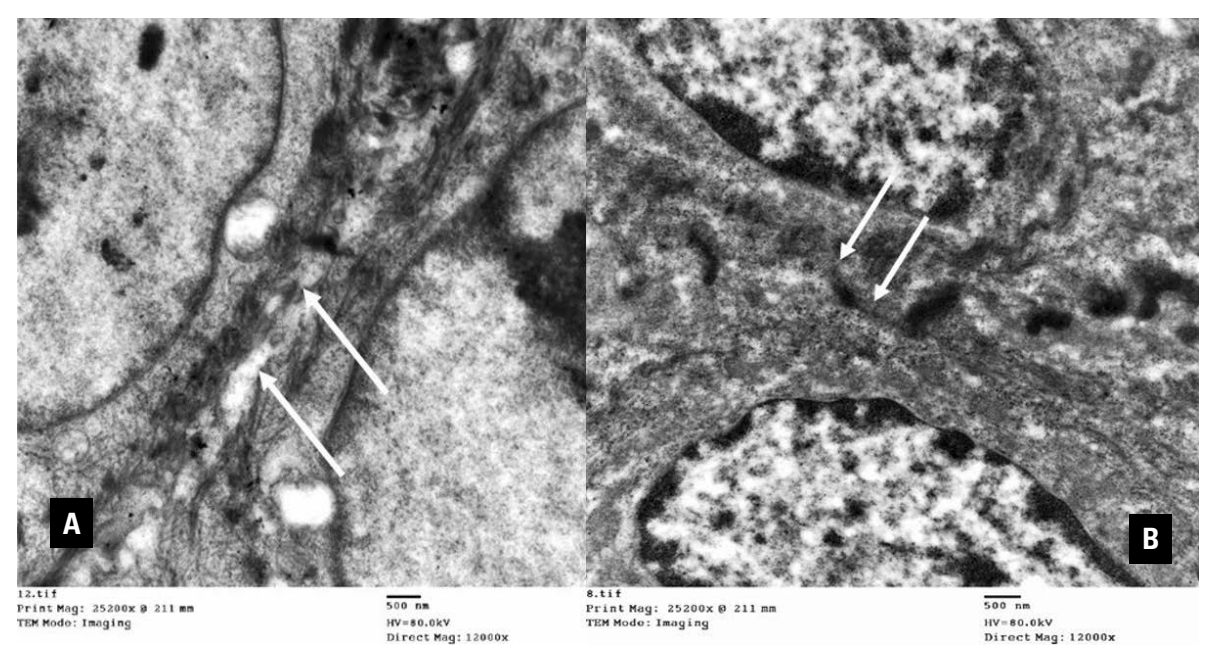

Figure 27. A. A higher magnification of a part of section of Figure $26 \mathrm{~A}$ showing the wide intercellular spaces between the epidermal cells where they lost their desmosomal connections (arrow); B. After receiving subcutaneous mesenchymal stem cells injection preceded by Aldara cream application showing stratum basale cells. The cells have processes that are connected together tightly by desmosomes (arrow); TEM $\times 12000$.

betamethasone-treated group III and non-significant increase in MSCs-treated group IV, compared to the control (group I). While in betamethasone-treated group III and MSCs-treated group IV, there was a highly significant decrease in the number of new blood vessel formation as compared to group II (IMQ-treated) $(p<0.001)$ (Table 1, Fig. 29).

\section{Inflammatory cells count}

The numbers of inflammatory cells in H\&E-stained sections under high power field of light microscope, revealed highly statistically significant increase in the number of inflammatory cells in group II (IMQ-treated) and in betamethasone-treated group III and non-significant increase in MSCs-treated group IV compared to the control (group I). While in betamethasone-treated group III and MSCs-treated group IV, there was a highly significant decrease in the number of inflammatory cells as compared to group II (IMQ-treated) $(p<0.001)$ (Table 1 Fig. 30).

\section{DISCUSSION}

The current work was designed to investigate the possible effect of human umbilical cord-derived MSCs 
Table 1. Histomorphometric parameters in the four study groups

\begin{tabular}{|c|c|c|c|c|}
\hline $\begin{array}{l}\text { Mean } \pm \text { standard } \\
\text { deviation of }\end{array}$ & $\begin{array}{l}\text { Control } \\
\text { group }\end{array}$ & $\begin{array}{c}\text { IMO- } \\
\text {-treated group }\end{array}$ & $\begin{array}{l}\text { Betamethasone- } \\
\text {-treated group }\end{array}$ & $\begin{array}{c}\text { MSCs- } \\
\text {-treated group }\end{array}$ \\
\hline Epidermal thickness/high & $0.5636 \pm 0.23$ & $6.28 \pm 1.06$ & $1.47 \pm 0.28$ & $0.8 \pm 0.3$ \\
\hline \multirow[t]{3}{*}{ power field } & & $(p<0.001)^{\mathrm{a}}$ & $(p<0.001)^{a}$ & $(p=0.05)^{b}$ \\
\hline & & & $(\mathrm{p}<0.001)^{\mathrm{d}}$ & $(p<0.001)^{d}$ \\
\hline & & & & $(p<0.001)^{e}$ \\
\hline \multirow[t]{4}{*}{ Blood vessels count } & $12.2 \pm 2.5$ & $36.2 \pm 5.11$ & $17.2 \pm 2.1$ & $15.4 \pm 1.7$ \\
\hline & & $(p<0.001)^{a}$ & $(\mathrm{p}<0.001)^{\mathrm{a}}$ & $(p=0.36)^{c}$ \\
\hline & & & $(p<0.001)^{d}$ & $(p<0.001)^{d}$ \\
\hline & & & & $(p=0.053)^{f}$ \\
\hline \multirow[t]{4}{*}{ Inflammatory cells count } & $17.2 \pm 0.81$ & $92 \pm 0.98$ & $27.1 \pm 3.1$ & $18.7 \pm 3.27$ \\
\hline & & $(p<0.001)^{a}$ & $(p<0.001)^{a}$ & $(p=0.07)^{c}$ \\
\hline & & & $(p<0.001)^{d}$ & $(p<0.001)^{d}$ \\
\hline & & & & $(p<0.001)^{e}$ \\
\hline
\end{tabular}

aHighly significant increase in comparison with control group; ${ }^{\circ}$ Significant increase in comparison with control group; 'Non-significant increase in comparison with control group; ${ }^{\text {HHighly }}$ significant decrease in comparison with IMQ-treated group; ${ }^{~} H$ ighly significant decrease in comparison with betamethasone-treated group; 'Significant decrease in comparison with betamethasone-treated group; IMO — imiquimod; MSC — mesenchymal stem cell

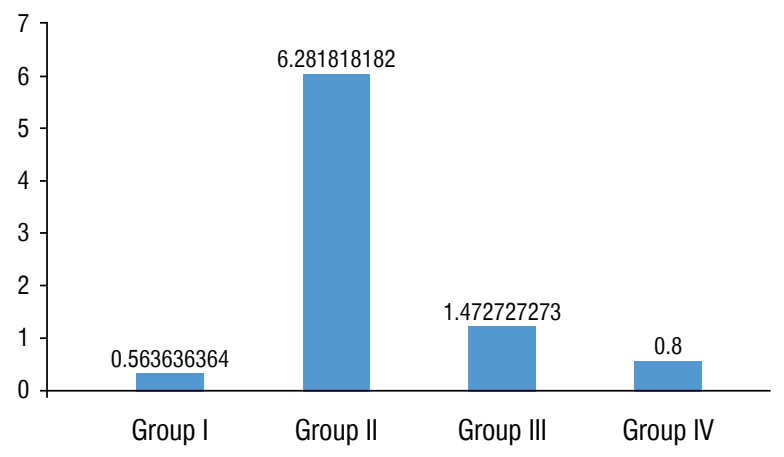

Figure 28. Mean thickness of the epidermis in micrometer.

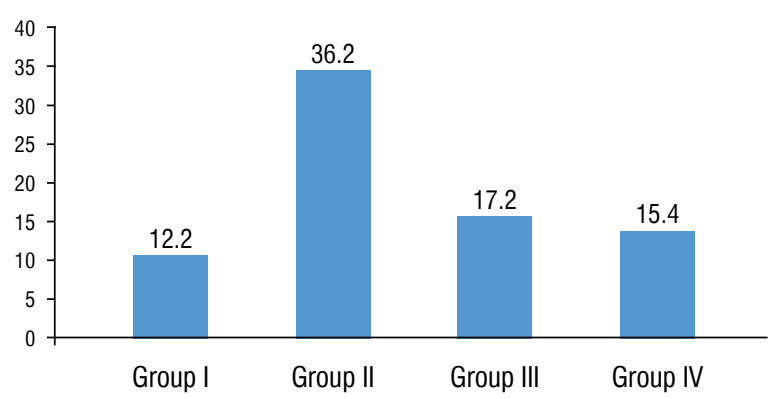

Figure 29. Mean blood vessels count.

versus conventional betamethasone cream treatment on imiquimod-induced psoriasis-like skin lesion in adult male albino rat model. Psoriasis appears to be a uniquely human disease, it exclusively affects human

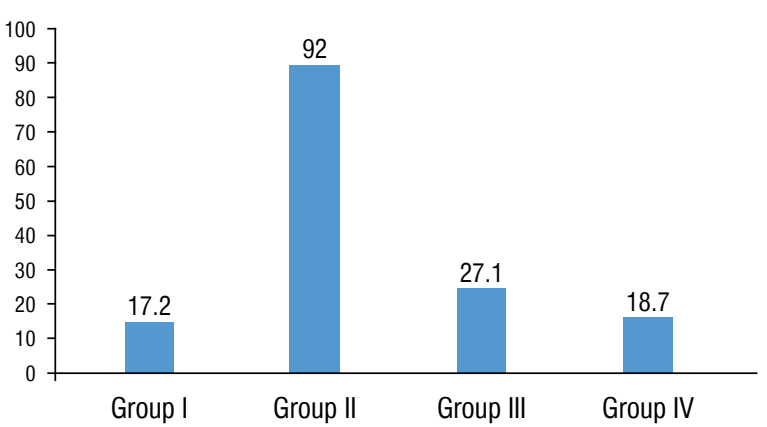

Figure 30. Mean inflammatory cells count.

among all animals with two reported exceptions; a rhesus monkey [24] and a cynomolgus monkey [40].

This lack of a suitable animal model has greatly hindered research into the pathogenesis and treatment of psoriasis. Over the past decades, numerous mouse models have been identified by genetic engineering and xenografting (human psoriatic skin grafted to immunodeficient mice) as an attempt to reproduce psoriasis. Extensive comparisons between these models have been made in different reviews [3, 9, 13]. However, not all these models reflect all clinical, histological and immunophenotypic characteristics of human psoriasis as described by Irfan et al. [16] who reported that imiquimod-induced psoriasis-like skin inflammation in mice model is considered to have the same and most closely resemblance with human psoriasis. 
Jason et al. [18] added that the IMQ mouse model offers scientists several excellent advantages; easy to use, inexpensive, and needs short treatment duration to elicit acute skin inflammation.

Nestle and Nickoloff [29] defined several criteria for an ideal psoriasis model which are: 1) epidermal changes based on keratinocyte hyperproliferation and altered differentiation; 2) papillomatosis (regular and symmetrical extension of rete ridges, separated by elongated dermal papillae); 3) presence of inflammatory cells including T cells, dendritic cells, and neutrophils; 4) altered vascularity. In the present study, gross examination of the skin treated by IMQ cream (group II) showed signs of acute skin inflammation as erythema, scaling and thickening (induration) after 2-3 days from the start of experiment. These signs gradually worsened with continued treatment till the end of the experiment. Similar findings were described by van der Fits et al. [39]. The results presented in the current work showed that IMQ-induced skin inflammation clearly and consistently fulfils the previous criteria 1, 2, 3, 4 .

These clinical features were explained by Bochenska et al. [3] who reported that the erythema represents the degree of vasodilatation in the dermis to which multiple cytokines (interleukin 1 [IL-1] and tumour necrosis factor alpha [TNF- $\alpha$ ]) and compounds like (NO, phospholipase A2, metabolites and histamine) from various cellular sources (keratinocytes, dendritic cells, mast cells) contribute. Skin thickness or induration is the result of increased keratinocytes proliferation due to stimulation by proinflammatory cytokines as well as dermal infiltration by inflammatory cells. Scaling reflects abnormal keratinocyte differentiation and maturation due to increased proliferation and the abnormal cytokine medium. Hence, squamous keratinocytes aberrantly retain intact nuclei (parakeratosis) and release few extracellular lipids that normally cement adhesions of corneocytes. Therefore, poorly adherent stratum corneum is formed and this results in the characteristic scales of psoriasis, a phenomenon typical for psoriasis skin lesions.

While the naked eye observation of the betamethasone-treated group (group II) and MSCs-treated group (group IV) in the present study showed that the psoriatic erythema, scaling and thickening were highly reduced compared with the IMQ group. However, in group III there were still some scales on the skin surface. While in group IV no erythema or scales were observed with normal hair regrowth.
Examination of H\&E-stained sections of IMQ-treated group of rats in the present study showed increased epidermal thickening (acanthosis) which was statistically highly significant compared to the control group. Also, retention of nuclei in the stratum corneum (parakeratosis) and absence of the granular layer was observed in contrast to the control group. These findings coincided with those of Sah et al. [36] and Chamcheu et al. [4] who added that these histological findings are interestingly mimicking those of human samples of patients with active psoriasis taken in the same study.

Also, in the present study examining $\mathrm{H} \& \mathrm{E}$-stained sections of IMQ-treated group showed widening of the intracellular spaces between keratinocytes was obviously observed and this was due to the intercellular oedema known as spongiosis that was reported by Murphy et al. [27] who added that spongiosis was observed in the early stage while it became minimal or absent in the fully developed clinical plaque due to extension of inflammatory cells migration from the papillary capillaries via the thinned supra-papillary plates into the epidermis (exocytosis).

Exocytosis was observed in the H\&E-stained sections of IMQ-treated group in the present study and confirmed by immunohistochemical staining of CD4 and CD8 cells as some inflammatory cells traversed into the epidermis through the irregular and discontinuous basement membrane.

Ghoreschi et al. [12] stated that the dermis of psoriatic skin is infiltrated predominantly by CD4-positive Th cells, which produce proinflammatory cytokines such as interferon (IFN)-c, TNF and IL-17. Also, elevated levels of IL-6, IL-8 and keratinocyte growth factor (transforming growth factor-alpha) are found in psoriatic lesions Thus, an intense cross-talk between immune cells and keratinocytes seems to establish an interactive cytokine network, responsible for the development of psoriasis.

In the present study, there was a statistical increase of the numbers of the inflammatory cells in the papillary dermis of the IMQ-treated group which was highly significant compared to the control group. It was found that the inflammatory infiltrate was largely composed of CD4 and CD8 T cells as confirmed by immunohistochemical staining using (CD4 and CD8) antibodies as markers for these cells which revealed positively immune stained CD4 and CD8 cells in the papillary dermis and they were visualized also in the epidermis. 
Similar findings were described by Hawkes et al. [14] and Ogawa et al. [30] who stated that activated CD4 and CD8 lymphocytes were initially considered to be equally important in the inflammation associated with psoriasis because large numbers of activated CD4 and CD8 lymphocytes were identified in the skin and peripheral blood of psoriatic patients.

Disruption of the basement membrane and the impairment of the skin barrier function was described as a feature for psoriasis in the mouse model by Raychaudhuri et al. [34] and was confirmed recently by the study of Jabeen et al. [17] who evaluated the disruption of skin barrier in the IMQ-treated mouse model by measuring the trans-epidermal water loss which reached a significant high value after 4 days of IMQ application.

The electron microscopic examination of the IMQ-treated group in the current work confirmed the light microscopic observations and showed that the intercellular spaces especially within the basal layer were considerably widened losing the desmosomal contacts in between the basal keratinocytes. Also, the resting basement membrane showed large gaps and absence of hemidesmosomes connecting it to the basal layer.

The present ultrastructure findings coincided with Natsumi et al. [28] who reported that several gaps of lamina densa of the basement membrane were detected in IMQ psoriasis model mouse.

In the current study, H\&E-stained sections of IMQ-treated group showed increased angiogenesis and immune cell infiltrations in the underlying dermis. These findings were obviously noticed and confirmed by Masson's trichrome stain.

In the present work, there was a statistical increase of the numbers of dermal blood vessels of the IMQ-treated group which was highly significant compared to the control group. This increased vascularisation was visualised also by immunohistochemical staining using (CD31) antibody as a marker for endothelial blood vessels which revealed plenty of positively stained new vascular endothelial cells in the wall of the dermal blood vessels mainly in the papillary layer of dermis. The positive immune staining also was seen in some areas of the epidermis.

On the other hand, close examination of H\&Estained sections of rats of betamethasone-treated group and MSCs-treated group in the present study showed some differences between them although both of them showed decrease in the epidermal thickening which was statistically highly significant compared to the IMQ group, but the thickness of the epidermis in betamethasone group was not uniform with some areas of apparent increased thickness with crowded basal layer and no sharp demarcation line between epidermis and dermis. However, the underlying dermis of the two groups showed a decrease in the newly formed blood vessels and the inflammatory cells, which was statistically highly significant compared to the IMQ group. This decreased vascularisation was visualized also by immunohistochemical staining using (CD31) antibody as a marker for endothelial blood vessels which revealed few, sporadic positively stained new vascular endothelial cells in the wall of the dermal blood vessels mainly in the papillary layer.

These findings were explained by Chen et al. [7] who reported that corticosteroids are potent anti-inflammatory agents that block several inflammatory pathways and induce apoptosis of inflammatory cells but could not promote the differentiation of keratinocytes and inhibit the proliferation of keratinocytes as well as suppressing cytokine production by $T$ cells, dendritic cells and keratinocytes. Thus, the mechanism of action of corticosteroids allows it to be only used in combination therapy with other topical agents that may improve their efficacy and safety profile over longer periods.

In group IV (MSCs-treated group), sections stained by H\&E showed uniform thickness of the epidermis lying on intact basement membrane where a clear border of demarcation was seen between the epidermis and dermis. These findings were confirmed by Masson's trichrome-stained sections and by the electron microscopic examination that showed no wide intercellular spaces between the epidermal basal layer where the cells connected tightly together by desmosomes and were connected with the basement membrane by hemidesmosomes.

These ultrastructure findings could be explained in view of the study of Shin et al. [38] who reported that the electron microscopic analysis revealed that subcutaneous injection of human adipose tissue-derived mesenchymal stem cells in an oxazolone-induced atopic dermatitis model remarkably reduced trans-epidermal water loss by restoring normal epidermal barrier functions which are keratinocyte differentiation, epidermis development, and establishment of intact basement membrane. 
In the present work, MSCs demonstrated efficacy in reduction of disease severity through regulating multiple pathways. Psoriatic symptoms, higher expression of inflammatory mediators, and the infiltration of immune cells to the skin were all alleviated after MSC administration. This shows that the MSC infusion had immunomodulatory and anti-inflammatory effects, thereby strongly inhibiting the severity and development of psoriasis as reported by other studies like Rokunohe et al. [35] who used adipose tissue-derived MSCs, Owczarczyk-Saczonek et al. [31] who used bone marrow-derived MSCs, Imai et al. [15] who used human amnion-derived MSCs and Chen et al. [6] who used hUCB-MSCs.

Immunohistochemical staining examination using (CD4 and CD8) antibodies in the MSCs-treated group in the current study revealed negative immune reaction. Similar findings were reported by Sah et al. [36]; Lee et al. [23] who added that MSCs can exert immunosuppressive effect by inducing apoptosis in CD8 T cells, inhibiting CD4 T cells proliferation and Th17 cell differentiation and induce regulatory $T$ cells (Treg) differentiation.

Th17 cell homeostasis is the relationship with Tregs, whose imbalance may lead to the development of psoriasis as described by Rafei et al. [33] who confirmed that MSCs inhibit the activity of the Th17 cell, reducing the expression of IL-17 and decreasing inflammatory cell infiltration in the central nervous system.

Park et al. [32] found that human embryonic MSCs in experimental autoimmune arthritis suppressed T-cell proliferation, and down-regulated pro-inflammatory cytokine production. Moreover, these therapeutic effects were associated with an increase in CD4 Treg cells, inhibition of Th17 cell formation, and inhibited osteoclast differentiation.

In the current study, it was strongly believed that the beneficial effect of the MSCs on prevention the severity and progression of psoriasis may be due to the regulation of immune cell infiltration especially Th17 cells and by regulating epidermal functions and differentiations as reported by Kim et al. [20] who stated that the serum level of the Th1 cytokines (TNF-alpha, IFN-a, IFN-c, and IL-27) and Th17 cytokines (IL-17A and IL-23) were dramatically reduced by MSCs, which means that subcutaneous-injection of MSCs inhibit systemic IMQ-induced inflammation.
Kim et al. [20] added that there was correlation of the data from the skin lesions with the serum data. These results suggested that MSCs suppress the Th1and Th17-associated cytokines and the psoriatic skin changes induced by IMQ.

The treatment and management of psoriasis is complex and depends on the patient's symptoms. The current clinical management of psoriasis generally involves topical corticosteroids and vitamin D3 analogues. However, the efficacy of topical agents has been reported to be limited for patients with moderate-to-severe psoriasis and is accompanied by side effects with long-term application. Moreover, systemic immunosuppressants including methotrexate and cyclosporine have been reported to carry the risk of teratogenicity and other side effects. More recently, new biological agents including anti-17 (secukinumab, ixekizumab, and brodalumab) and anti-23 (tildrakizumab, guselkumab, and risankizumab) antibodies have been approved for the treatment of psoriatic disease. However, they are expensive and several adverse reactions have been also reported [14]. Therefore, alternative treatment with more efficacy and safety is important in psoriasis.

A recent comprehensive review discussed by Park et al. (2021) [32] who reported that 6 patients affected by psoriasis were described in 4 clinical studies. Despite significant differences in their therapeutic protocols and clinical outcomes, the MSC-based regimens were efficacious in $100 \%$ of the cases. Chen et al. [5], reported 2 cases of patients affected by psoriasis vulgaris treated with umbilical cord derived MSCs (hUCB-MSCs). Both of them had no recurrence for 4 years. They assumed that MSCs might be involved in the following four aspects: migration to skin lesions, immunomodulation, limitation of autoimmunity. However, they caution that more cases are needed to determine the efficacy of hUCB-MSCs and their infusion dose, method, and delivery time.

\section{CONCLUSIONS}

The data presented here suggest that the application of hUCB-MSCs raises hope for developing a new, safe and effective therapy for psoriatic patients, although it still requires a lot of new research.

Conflict of interest: None declared 


\section{REFERENCES}

1. Akeshita J, Grewal S, Langan S, et al. Psoriasis and comorbid diseases. J Am Acad Dermatol. 2017; 76(3): 393-403, doi: 10.1016/j.jaad.2016.07.065.

2. Bancroft JD, Gamble M. Theory and Practice of Histological Techniques. 6th ed. Churchill Livingstone, London 2008: London.

3. Bocheńska K, Smolińska $E$, Moskot $M$, et al. Models in the research process of psoriasis. Int J Mol Sci. 2017; 18(12), doi: 10.3390/ijms18122514, indexed in Pubmed: 29186769.

4. Chamcheu JC, Chaves-Rodriquez MI, Adhami VM, et al. Upregulation of PI3K/AKT/mTOR, FABP5 and PPAR $\beta / \delta$ in human psoriasis and imiquimod-induced murine psoriasiform dermatitis model. Acta Derm Venereol. 2016; 96(6): 854-856, doi: 10.2340/00015555-2359, indexed in Pubmed: 26833029.

5. Chen Hu, Niu JW, Ning HM, et al. Treatment of psoriasis with mesenchymal stem cells. Am J Med. 2016; 129(3): e13-e14, doi: 10.1016/j.amjmed.2015.11.001, indexed in Pubmed: 26582058.

6. Chen M, Peng J, Xie Qi, et al. Mesenchymal stem cells alleviate moderate-to-severe psoriasis by reducing the production of type i interferon (IFN-I) by plasmacytoid dendritic cells (pDCs). Stem Cells Int. 2019; 2019: 6961052, doi: 10.1155/2019/6961052, indexed in Pubmed: 31827531.

7. Chen W, Gong Yu, Zhang $X$, et al. Decreased expression of IL-27 in moderate-to-severe psoriasis and its anti-inflammation role in imiquimod-induced psoriasis-like mouse model. J Dermatol Sci. 2017; 85(2): 115-123, doi: 10.1016/j.jdermsci.2016.11.011, indexed in Pubmed: 27939414

8. Connick P, Kolappan M, Crawley C, et al. Autologous mesenchymal stem cells for the treatment of secondary progressive multiple sclerosis: an open-label phase $2 \mathrm{a}$ proof-of-concept study. Lancet Neurology. 2012; 11(2): 150-156, doi: 10.1016/s1474-4422(11)70305-2.

9. Conrad C, Nestle FO. Animal models of psoriasis and psoriatic arthritis: an update. Curr Rheumatol Rep. 2006; 8(5): 342-347, doi: 10.1007/s11926-006-0063-x, indexed in Pubmed: 16973107.

10. de la Portilla F, Alba F, García-Olmo D, et al. Expanded allogeneic adipose-derived stem cells (eASCs) for the treatment of complex perianal fistula in Crohn's disease: results from a multicenter phase I/lla clinical trial. Int J Colorectal Dis. 2013; 28(3): 313-323, doi: 10.1007/s00384-0121581-9, indexed in Pubmed: 23053677.

11. Drury R, Wallington E. Carleton's Histologiacal Technique. 5th ed. London, New York, Tronto 1980: 520.

12. Ghoreschi K, Weigert C, Röcken M. Immunopathogenesis and role of T cells in psoriasis. Clin Dermatol. 2007; 25(6): 574-580, doi: 10.1016/j.clindermatol.2007.08.012, indexed in Pubmed: 18021895.

13. Gudjonsson JE, Johnston A, Dyson M, et al. Mouse models of psoriasis. J Invest Dermatol. 2007; 127(6): 1292-1308, doi: 10.1038/sj.jid.5700807, indexed in Pubmed: 17429444.

14. Hawkes JE, Chan TC, Krueger JG. Psoriasis pathogenesis and the development of novel targeted immune therapies. J Allergy Clin Immunol. 2017; 140(3): 645-653, doi: 10.1016/j.jaci.2017.07.004, indexed in Pubmed: 28887948.

15. Imai $Y$, Yamahara $K$, Hamada A, et al. Human amnion-derived mesenchymal stem cells ameliorate imiquimod-induced psoriasiform dermatitis in mice. J Dermatol. 2019; 46(3): 276-278, doi: 10.1111/1346-8138.14768, indexed in Pubmed: 30632187.

16. Irfan $A R$, Vivek $K B$, Jonghun $H$, et al. Imiquimod-induced psoriasis-like skin inflammation in mouse model. Bangladesh J Pharmacol. 2016; 11(4): 849-851, doi: 10.3329/ bjp.v11i4.28662.

17. Jabeen M, Boisgard AS, Danoy A, et al. Advanced characterization of imiquimod-induced psoriasis-like mouse model. Pharmaceutics. 2020; 12(9), doi: 10.3390/pharmaceutics12090789, indexed in Pubmed: 32825447.

18. Jason EH, Johann G, Nicole $W L$, et al. The snowballing literature on imiquimod-induced skin inflammation in mice: a critical appraisal. J Invest Dermatol. 2017; 137(3): 546-549, doi: 10.1016/j.jid.2016.10.024, indexed in Pubmed: 27955901.

19. Kern S, Eichler H, Stoeve J, et al. Comparative analysis of mesenchymal stem cells from bone marrow, umbilical cord blood, or adipose tissue. Stem Cells. 2006; 24(5): 1294-1301, doi: 10.1634/stemcells.2005-0342, indexed in Pubmed: 16410387.

20. Kim CH, Lim CY, Lee JH, et al. Human embryonic stem cells-derived mesenchymal stem cells reduce the symptom of psoriasis in imiquimod-induced skin model. Tissue Eng Regen Med. 2019; 16(1): 93-102, doi: 10.1007/s13770018-0165-3, indexed in Pubmed: 30815354.

21. Kim HS, Yun JW, Shin TH, et al. Human umbilical cord blood mesenchymal stem cell-derived PGE2 and TGF- $\beta 1$ alleviate atopic dermatitis by reducing mast cell degranulation. Stem Cells. 2015; 33(4): 1254-1266, doi: 10.1002/ stem.1913, indexed in Pubmed: 25522163.

22. Kim KH, Blasco-Morente G, Cuende N, et al. Mesenchymal stromal cells: properties and role in management of cutaneous diseases. J Eur Acad Dermatol Venereol. 2017; 31(3): 414-423, doi: 10.1111/jdv.13934, indexed in Pubmed: 27549663.

23. Lee YS, Sah SK, Lee JiH, et al. Human umbilical cord blood-derived mesenchymal stem cells ameliorate psoriasis-like skin inflammation in mice. Biochem Biophys Rep. 2017; 9: 281-288, doi: 10.1016/j.bbrep.2016.10.002, indexed in Pubmed: 28956015.

24. Lowe NJ, Breeding J, Kean C, et al. Psoriasiform dermatitis in a rhesus monkey. J Invest Dermatol. 1981; 76: 141-142.

25. Lowes M, Suárez-Fariñas M, Krueger J. Immunology of psoriasis. Ann Rev Immunol. 2014; 32(1): 227-255, doi: 10.1146/annurev-immunol-032713-120225.

26. Mori H, Arita K, Yamaguchi T, et al. Effects of topical application of betamethasone on imiquimod-induced psoriasis-like skin inflammation in mice. Kobe J Med Sci. 2016; 62(4): E79-E88, indexed in Pubmed: 28239073.

27. Murphy M, Kerr P, Grant-Kels JM. The histopathologic spectrum of psoriasis. Clin Dermatol. 2007; 25(6): 524-528, doi: $10.1016 /$ j.clindermatol.2007.08.005, indexed in Pubmed: 18021888.

28. Natsumi A, Sugawara K, Yasumizu M, et al. Re-investigating the basement membrane zone of psoriatic epidermal lesions: is laminin-511 a new player in psoriasis patho- 
genesis? J Histochem Cytochem. 2018; 66(12): 847-862, doi: 10.1369/0022155418782693, indexed in Pubmed: 29906214

29. Nestle FO, Nickoloff BJ. Animal models of psoriasis: a brief update. J Eur Acad Dermatol Venereol. 2006; 20(s2): 24-27, doi: 10.1111/j.1468-3083.2006.01769.x.

30. Ogawa E, Sato Y, Minagawa A, et al. Pathogenesis of psoriasis and development of treatment. J Dermatol. 2018; 45(3): 264-272, doi: 10.1111/1346-8138.14139, indexed in Pubmed: 29226422.

31. Owczarczyk-Saczonek A, Krajewska-Włodarczyk M, Kruszewska $A$, et al. Stem cells as potential candidates for psoriasis cell-replacement therapy. Int J Mol Sci. 2017; 18(10), doi: 10.3390/ijms18102182, indexed in Pubmed: 29053579.

32. Park MJ, Park HS, Cho ML, et al. Transforming growth factor beta-transduced mesenchymal stem cells ameliorate experimental autoimmune arthritis through reciprocal regulation of Treg/Th17 cells and osteoclastogenesis. Arthritis Rheum. 2011; 63(6): 1668-1680, doi: 10.1002/ art.30326, indexed in Pubmed: 21384335.

33. Rafei M, Campeau PM, Aguilar-Mahecha A, et al. Mesenchymal stromal cells ameliorate experimental autoimmune encephalomyelitis by inhibiting CD4 Th17 T cells in a CC chemokine ligand 2-dependent manner. J Immunol. 2009; 182(10): 5994-6002, doi: 10.4049/jimmunol.0803962, indexed in Pubmed: 19414750.

34. Raychaudhuri SK, Maverakis E, Raychaudhuri SP. Diagnosis and classification of psoriasis. Autoimmun Rev. 2014; 13(4-5): 490-495, doi: 10.1016/j.autrev.2014.01.008, indexed in Pubmed: 24434359.

35. Rokunohe A, Matsuzaki Y, Rokunohe D, et al. Immunosuppressive effect of adipose-derived stromal cells on imiquimod-induced psoriasis in mice. J Dermatol Sci. 2016; 82(1): 50-53, doi: 10.1016/j.jdermsci.2015.12.007, indexed in Pubmed: 26778737.

36. Sah SK, Park KHo, Yun CO, et al. Effects of human mesenchymal stem cells transduced with superoxide dismutase on imiquimod-induced psoriasis-like skin inflammation in mice. Antioxid Redox Signal. 2016; 24(5): 233-248, doi: 10.1089/ars.2015.6368, indexed in Pubmed: 26462411.

37. Sawilowsky S. Misconceptions leading to choosing the t test over the wilcoxon Mann-Whitney test for shift in location parameter. J Mod App Stat Methods. 2005; 4(2): 598-600, doi: 10.22237/jmasm/1130804700.

38. Shin KO, Ha DH, Kim JO, et al. Exosomes from human adipose tissue-derived mesenchymal stem cells promote epidermal barrier repair by inducing de novo synthesis of ceramides in atopic dermatitis. Cells. 2020; 9(3), doi: 10.3390/cells9030680, indexed in Pubmed: 32164386.

39. van der Fits L, Mourits S, Voerman JSA, et al. Imiquimod-induced psoriasis-like skin inflammation in mice is mediated via the IL-23/IL-17 axis. J Immunol. 2009; 182(9): 5836-5845, doi: 10.4049/jimmunol.0802999, indexed in Pubmed: 19380832.

40. Zanolli MD, Jayo MJ, Jayo JM. Evaluation of psoriatic plaques that spontaneously developed in a cynomolgus monkey (Macaca fascicularis). Acta Derm Venereol Suppl (Stockholm. 1989; 146: 58.

41. Zhou H, Guo M, Bian C, et al. Efficacy of bone marrow-derived mesenchymal stem cells in the treatment of sclerodermatous chronic graft-versus-host disease: clinical report. Biol Blood Marrow Transplant. 2010; 16(3): 403-412, doi: 10.1016/j.bbmt.2009.11.006, indexed in Pubmed: 19925878. 